\title{
Model Predictive Controlled SLQZSI Fed IM Drive with Quick Response
}

\author{
V. Malathi, D. Vijayakumar
}

\begin{abstract}
This paper presents a model predictive controlled switched inductor quasi $\mathrm{Z}$ source inverter fed induction motor drive with quick response. MPC depends on dynamic models of the process and more frequently linear empirical models are arrived trough drive system identification. The unique nature of MPC has control logic to optimize the induction motor speed while considering the further speed. Modeling of MPC controlled SLQZSI fed IM is obtained through simulation under MATLAB platform and experimental work. The performance of closed loop controlled SLQZSI fed IM drive is analyzed in terms of rise time, settling tim, peak time and steady state error. The outcomes shows that the reaction of MP controlled SLQZSI fed IM drive are quicker than that of PI and FOPID controlled SLQZSI fed IM.
\end{abstract}

Keywords : FOPID, Model predictive controller, Peak time, Rise time, Settling time, switched inductor quasi z source inverter, Steady state error, Induction motor drives.

\section{INTRODUCTION}

Upgraded improved QZSI through double switched impedance circuits for topologies is exhibited for the improved boost QZSI, to be specific consistent into current design and irregular information current arrangement of enhanced boost QZSI with exchanged impedance frameworks. Like upgraded boost ZSI's, this inverter methodologies have exceptionally higher improved voltage reversal at lesser shoot through duty proportion and more regulation yields an improved quality of voltage [1]. A power saved quasi z-source cascade MLI hinged PV power production frameworks utilizing quasi Z-source CMI presents numerous preferences over regular CMI when connected in PV energy frameworks. At instance, the QZS-CMI gives the reasonable voltage boost-capacity and dc-link voltage, spares 33\% modules, and so on. In any case, the QZS-CMI can't defeat the discontinuous and vacillation of sun oriented power fed to the power system [2]. DC-interface voltage balance control procedure dependent on multidimensional regulation strategy for QZS-CMLI PV power framework [3]. Switching misfortune decrease in the three phase QZSI using changed space vector regulation procedures among them a few single phase topologies have been presented Besides, unique regulation systems, using numerous reference signals, have been created as well [4].

Revised Manuscript Received on December 30, 2019.

* Correspondence Author

V. Malathi, Research Scholar, Department of EEE, SCSVMV University, Kanchipuram-631 561 (Tamil Nadu) India.

D. Vijayakumar, Professor, School of Electrical Engineering, VIT University, Vellore-632 014 (Tamil Nadu) India.

(c) The Authors. Published by Blue Eyes Intelligence Engineering and Sciences Publication (BEIESP). This is an open access article under the CC BY-NC-ND license (http://creativecommons.org/licenses/by-nc-nd/4.0/)
Enhanced boost QZSI through a dynamic switched Z network was contrasted with improved boost QZSI through two exchanged impedance circuits, recommended inverter have asimilar elevated boost factor whereas utilizing two LC sets and one diode and just includes one exchanging gadget. Likewise, current stress over switches is decreased considerably, which prompts critical decrease in the transmission failure of switches and meliorates proficiency of the general inverter [5].

Direct MPC procedure of QZSI was exhibits a direct MPC technique for QZSI's. A discrete-time demonstrates is determined that precisely catches every single working method of the converter. In recent development of progressively electric flying devices, dc bus voltage is changeable because of the uneven speed of generator. This infers obliges to structure the actuator for the most reduced dc voltage esteem [6].

Two extended boost symmetric embedded structures with equal and less voltage on the capacitors and in switched inductor in the $\mathrm{Z}$ source circuit. The proposed structures have lesser ripple continuous input current and higher voltage gain for smaller duty cycle ratio [7].

Two configurations with two switched impedance network of enhanced boost QZSI. The paper elaborates the working theory and investigation of constant input current arrangement. By sharing general common between supply and bridge inverter, the proposed topology defeats the preliminary inrush trouble and consumes constant current by lesser capacitor voltages [8]. A novel more boost single-stage quasi-Z-source inverter was introduced and it is depend on the dynamic switched Z-impedance circuit. The planned scheme has lesser lively switching voltage strain, lesser voltage rating of inert component, lower ripple content in the supply current and lower shoot through current stress [9]. A new topology and investigated SLQSI performance in dissimilar working methods. The expression for current and voltage of every one component are obtained and serious inductance values are designed. Power losses and efficiency investigations are obtained [10]. A novel space vector inflection strategy is to decrease inductor current swell in z-source inverter. In real time shoot-through times are divided by using the theory of volt-second equilibrium. The unequal every divided shoot-through time ensure that the inductor charging and discharging current ripple is zero at every instance. Hence inductor current swell is reduced [11].

The photovoltaic (PV) linked power system; low voltage is boosted to high voltage with high step-up switched Z-source dc-dc converters. Saturation of inductor causes instability, which can be avoided by smaller duty cycle or higher boost factor [12]. 
An uneven switching indicate projecting current manage for QZSI is presented [13]. The work plans to eliminate the errors on ac side such as output current and errors in dc region such as capacitor voltage and inductor current of QZSI network. The switching signals can be applied at several moments inside the sampling period, lesser than the shoot through time condition. Hence results in lesser tipple in output current and inductor current. For a system linked QZSI, a MPC is proposed [14]. Through momentary and stable situation working, the grid current is controlled by including switching frequency and capacitor voltage as control constraints.

MPC modelling for the voltage of SLN is modelled to forecast the ratings in prospect. Cost function is composed by comparing the predict values with reference value. Minimum cost function is achieved by selecting the switching state.MPC tracks the mention ratings of the forced variables hence making the system to respond faster [15]. A new MPC method with constant switching frequency is implemented, utilises small computational time and easy to implement. The optimal voltage vector is found based on gradient descent method. Proposed method is applied to analysis the performance of single inverter or parallel inverter operation [16].

\section{SL-QZSI TOPOLOGY}

The planned SL-QZSI methodoloy is given in Fig. 1, it has three inductors $\left(\mathrm{L}_{1}, \mathrm{~L}_{2}\right.$, and $\left.\mathrm{L}_{3}\right)$, two capacitors $\left(\mathrm{C}_{1}\right.$ and $\left.\mathrm{C}_{2}\right)$, and four diodes $\left(D_{1}, D_{1}, D_{2}\right.$, and $\left.D_{3}\right)$. The arrangement of $\mathrm{L}_{2}-\mathrm{L}_{3}-\mathrm{D}_{1}-\mathrm{D}_{2}-\mathrm{D}_{3}$ acts as a SL cell.

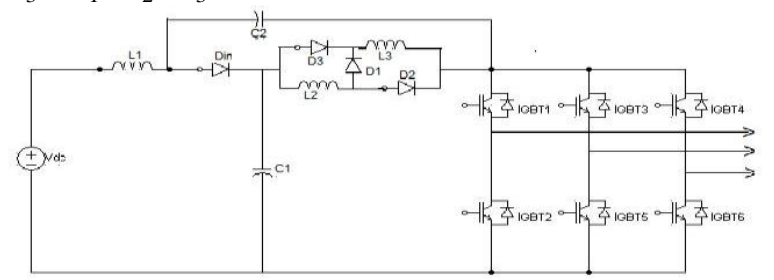

Fig. 1. SL-QZSI topology

Though at initial resonance is supplied by source impedance of inductor and capacitors and now no current flows to the central power supply. Therefore, the planned topology is suppressing the in rush current. The proposed inverter raises the boost factor from $1 /(1-2 \mathrm{D})$ to $(1+\mathrm{D}) /(1-2 \mathrm{D}-\mathrm{D} 2)$.

\section{A. Circuit Analysis}

The planned SL-QZSI have conventional six dynamic, two zero conditions and additional shoot-through zero status similar to traditional ZSI. Therefore, the working theory of together planned inverter and the conventional ZSIs are comparable. The working conditions of planned SL-QZSI are categorized into non shoot-through and shoot through states.

Non- shoot- through state:

In the non-shoot-through situation the planned inverter has six dynamic conditions and two zero conditions. In this condition, $\mathrm{D}_{\text {in }}$ and $\mathrm{D}_{1}$ are on, whereas diodes $\mathrm{D}_{2}$ and $\mathrm{D}_{3}$ are off. Inductors $\mathrm{L}_{2}$ and $\mathrm{L}_{3}$ are connected in sequence. The capacitors $C_{1}$ and $C_{2}$ are excited, whereas the inductors $L_{1}$, $\mathrm{L}_{2}$, and $\mathrm{L}_{3}$ convey power from the dc input supply to the focal power circuit. $\mathrm{V}_{\mathrm{L} 2}$ non and $\mathrm{V}$ L3_non are the consequent voltages across $\mathrm{L}_{2}$ and $\mathrm{L}_{3}$ correspondingly. Fig. 2(a) and Fig. 2(b) show the non- shoot through operating state and reduced equivalent circuit of SL-QZSI under non-shoot-through state.

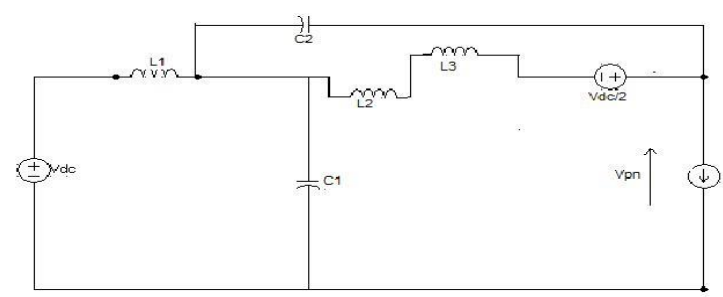

Fig. 2(a). Non- shoot-through operating state
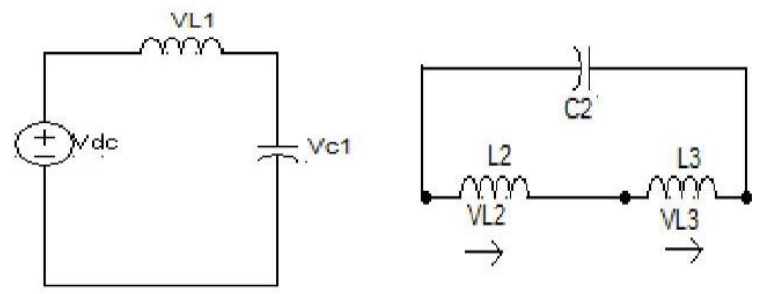

Fig. 2(b). Reduced Equivalent circuit of SL-QZSI under Shoot- through state: non- shoot-through state

This situation arises while together the higher and inferior controlling locations. The shoot- through state recurs regularly each components of some phase leg of the inverter is connected. The shoot-through operating condition and equivalent circuit of SL-QZSI under shoot-through state is presented in Fig. 3(a) and Fig. 3(b). Through shoot- through state, $D_{\text {in }}$ and $D_{1}$ are off, while $D_{2}$ and $D_{3}$ are on. The inductors $\mathrm{L}_{2}$ and $\mathrm{L}_{3}$ are joined in parallel and the capacitors C1 and C2 are discharged, while inductors $L_{1}, L_{2}$, and $L_{3}$ store the energy.

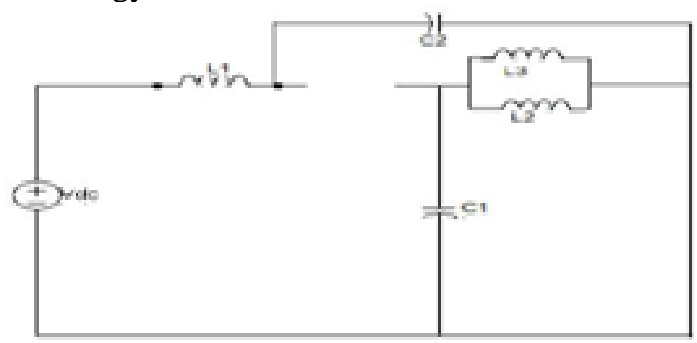

Fig. 3(a). Shoot-through operating state
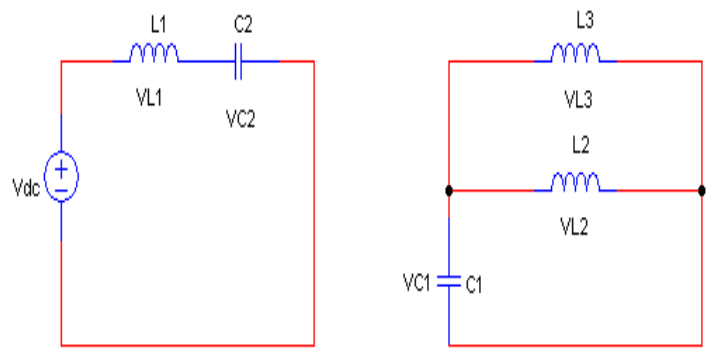

Fig. 3(b). Reduced Equivalent circuit of SL-QZSI in shoot-through state 


\section{SL-QZSI FED INDUCTION MOTOR WITH MP CONTROLLER}

DC from the yield of semi-converter is applied to SL-Network. The DC yield of the SL network is connected to the inverter. The VSI is used to have power over the speed of the drive for fluctuating AC voltage. The DC voltage of the semi-converter is controlled by utilizing (FOPID) to lessen the settling-time. The block diagram of open loop SLQZSI fed IM drive arrangement is given in Fig. 4. The block diagram of closed loop SLQZSI fed IM with PI controller is shown in Fig. 5. The block diagram of closed loop SLQZSI fed IM drive with FOPID-controller is shown in Fig. 6. The block diagram of planned closed loop SLQZSI fed IM drive with MP controller is shown in Fig. 7.

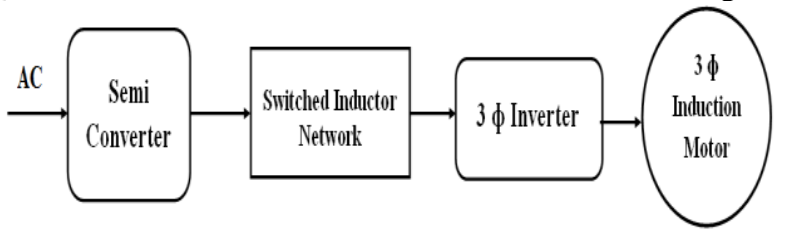

Fig. 4. Block diagram of open loop SLQZSI fed IM

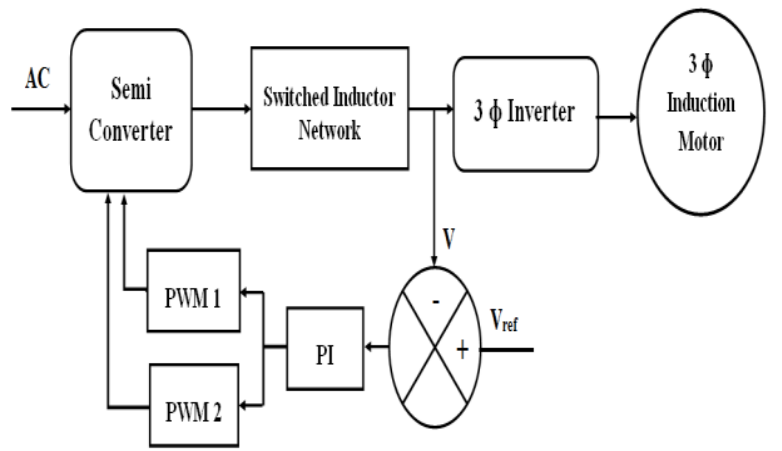

Fig. 5. Block diagram of Closed loop SLQZSI-IM with PI controller

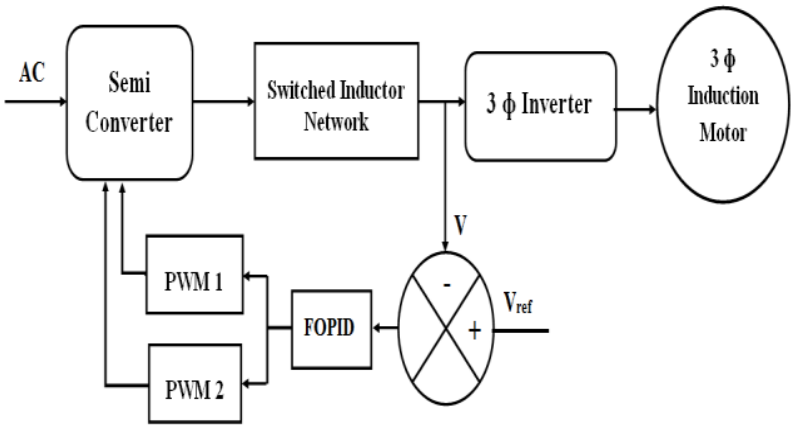

Fig. 6. Block diagram of closed loop SLQZSI-IM with FOPID controller

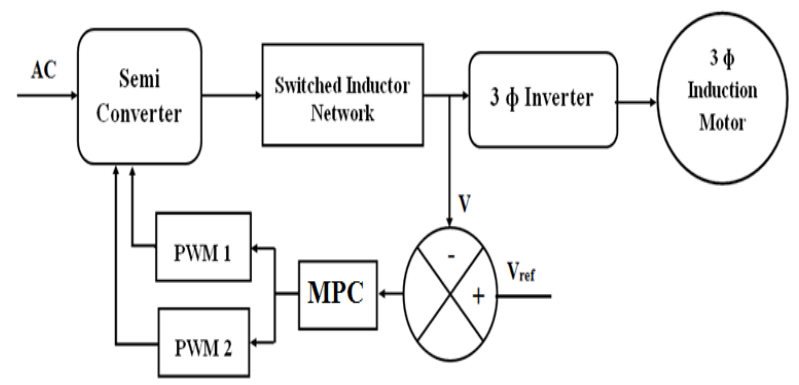

Fig. 7. Block diagram of closed loop SLQZSI-IM with MP controller

\section{SIMULATION RESULTS}

A.Closed loop SLQZSI fed IM with FOPID controller

Closed control loop SLQZSI fed induction motor with FOPID controller is modeled and simulated using Matlab is displayed in Fig. 10. The AC input voltage of 200V (peak amplitude), $50 \mathrm{~Hz}$ are applied to SLQZSI fed IM with FOPID controller is laid out in Fig. 8. Voltage across SLQZSI fed induction motor with FOPID controller is displayed in Fig. 9. Voltae acroos motor load is $250 \mathrm{~V}$ of inverter in SLQZSI fed IM with FOPID controller is show in Fig. 11. Fig. 12 presents the current through motor of SLQZSI fed induction motor with FOPID controller and its value is $0.01 \mathrm{~A}$. Motor speed of $1010 \mathrm{rpm}$ and torque of $0.25 \mathrm{~N}-\mathrm{m}$ of SLQZSI fed induction motor is displayed in Fig. 13 and Fig. 14 reciprocally.

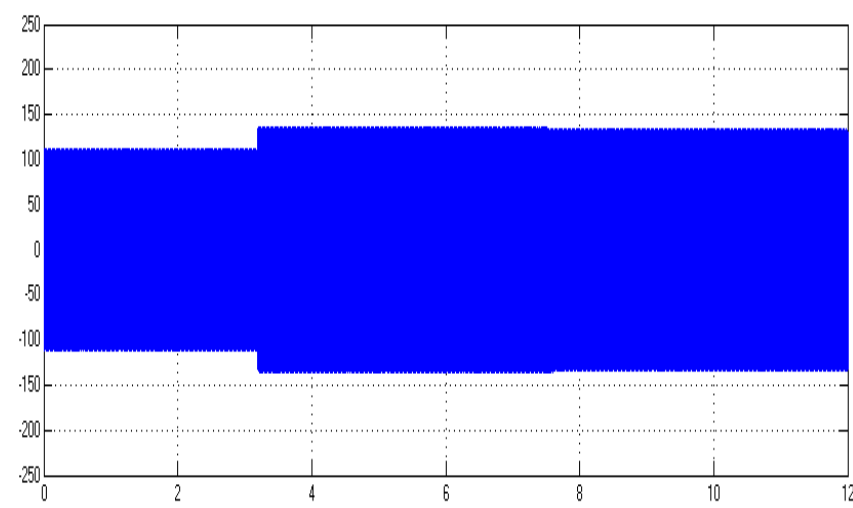

Fig. 8. AC input voltage of SLQSI fed IM with FOPID controller

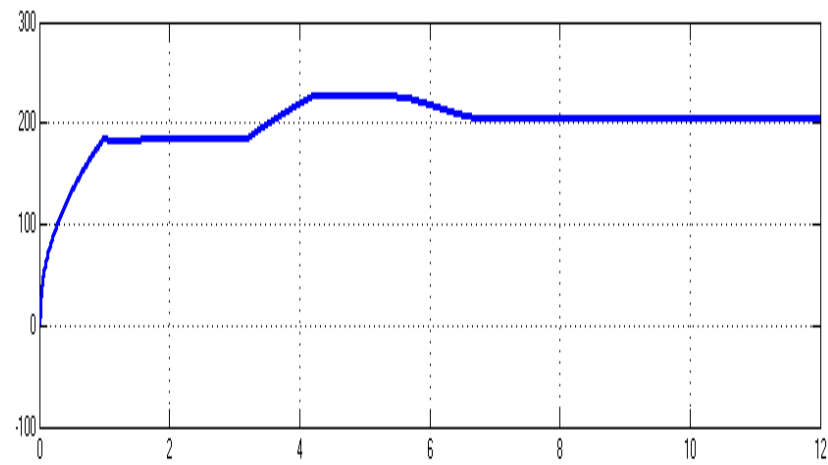

Fig. 9. Output voltage of SLQZSI fed IM with FOPID controller 


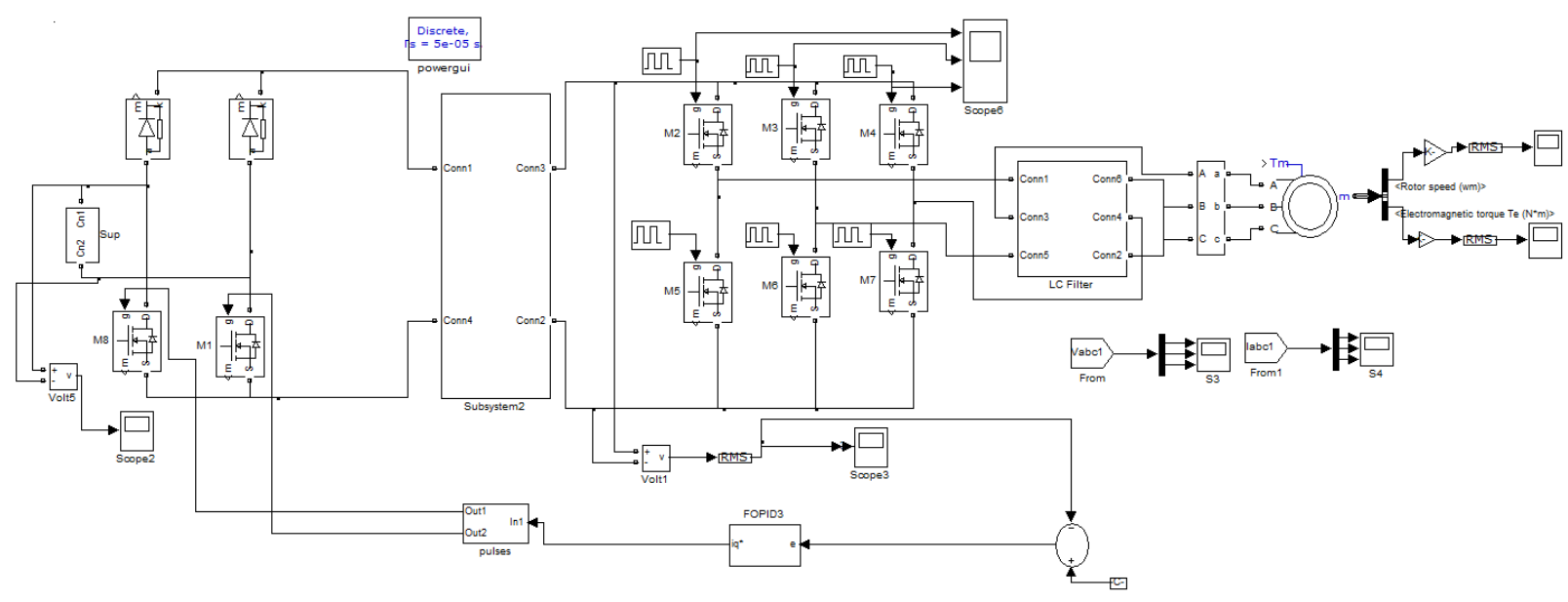

Fig. 10.Simulation diagram of Closed control loop SLQZSI-IM with FOPID controller

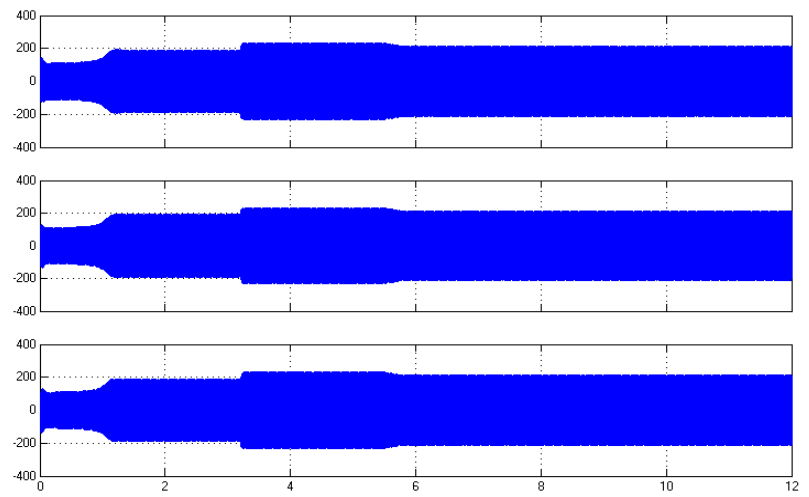

Fig. 11. Voltage across moto load of SLQZSI fed IM with FOPID controller
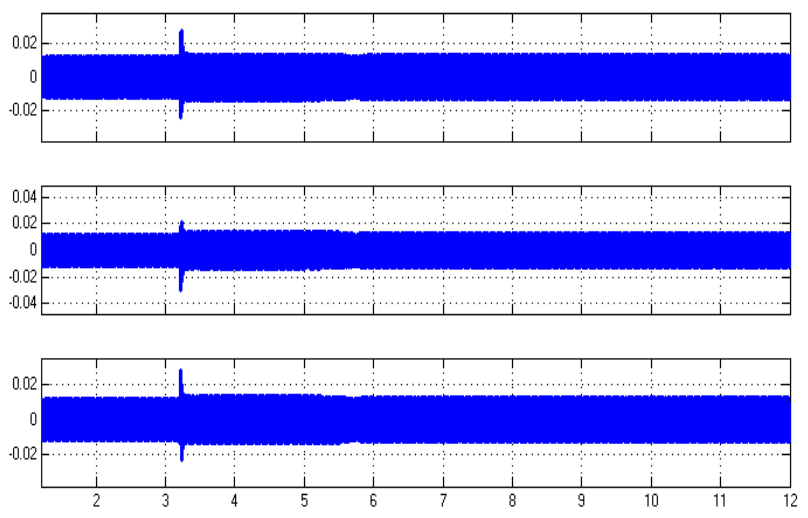

Fig. 12. Current through motor of SLQZSI fed IM with FOPID controller

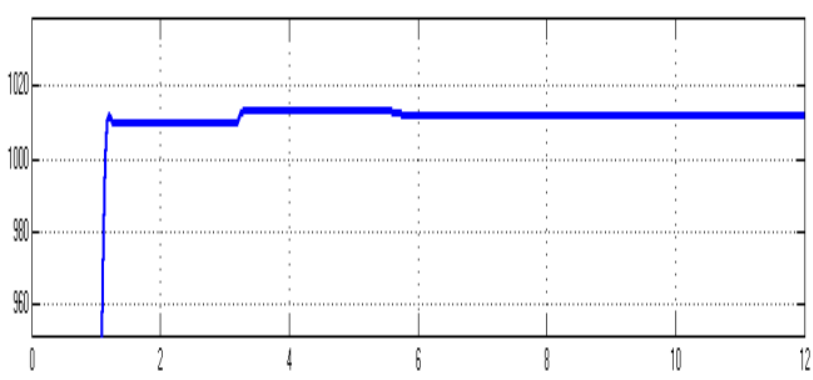

Fig. 13. Motor speed of SLQZSI fed IM with FOPID controller

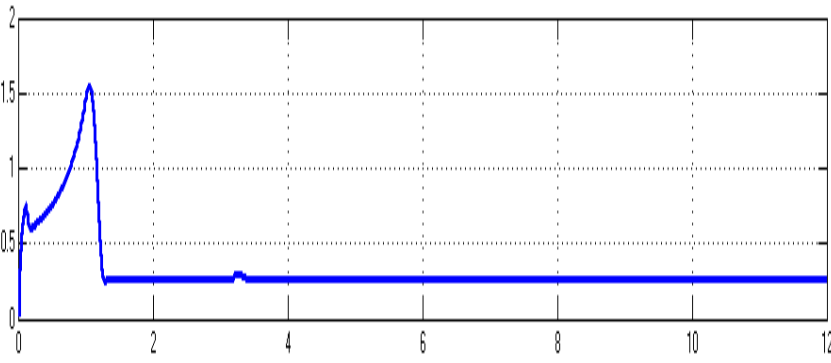

Fig. 14. Motor Torque of SIQZSI fed IM with FOPID controller

\section{B. Closed loop SLQZSI fed IM with MP controller}

Closed control loop SLQZSI fed induction motor with FOPID controller is modeled and simulated using Matlab is displayed in Fig. 16. The AC input voltage of 200V (peak amplitude), $50 \mathrm{~Hz}$ are applied to SLQZSI fed IM with MP controller is laid out in Fig. 15. Voltage across SLQZSI fed induction motor with MP controller is displayed in Fig. 17. Voltae acroos motor load is $200 \mathrm{~V}$ of inverter in SLQZSI fed IM with MP controller is show in Fig. 18. Fig. 19 presents the current through motor of SLQZSI fed induction motor with FOPID controller and its value is 0.01A. Motor speed of $1110 \mathrm{rpm}$ and torque of $0.25 \mathrm{~N}$-m of SLQZSI fed induction motor is displayed in Fig. 20 and Fig. 21 reciprocally.

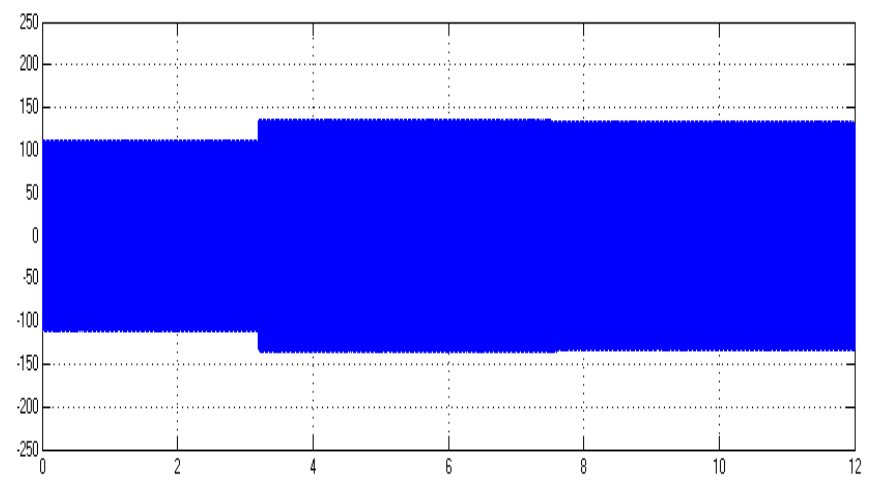

Fig. 15. AC input voltage of SLQSI fed IM with MP controller

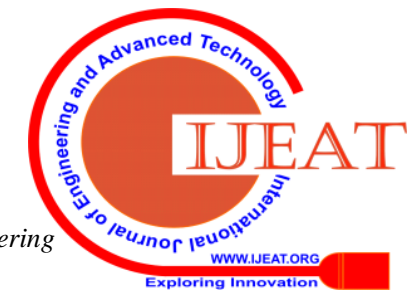




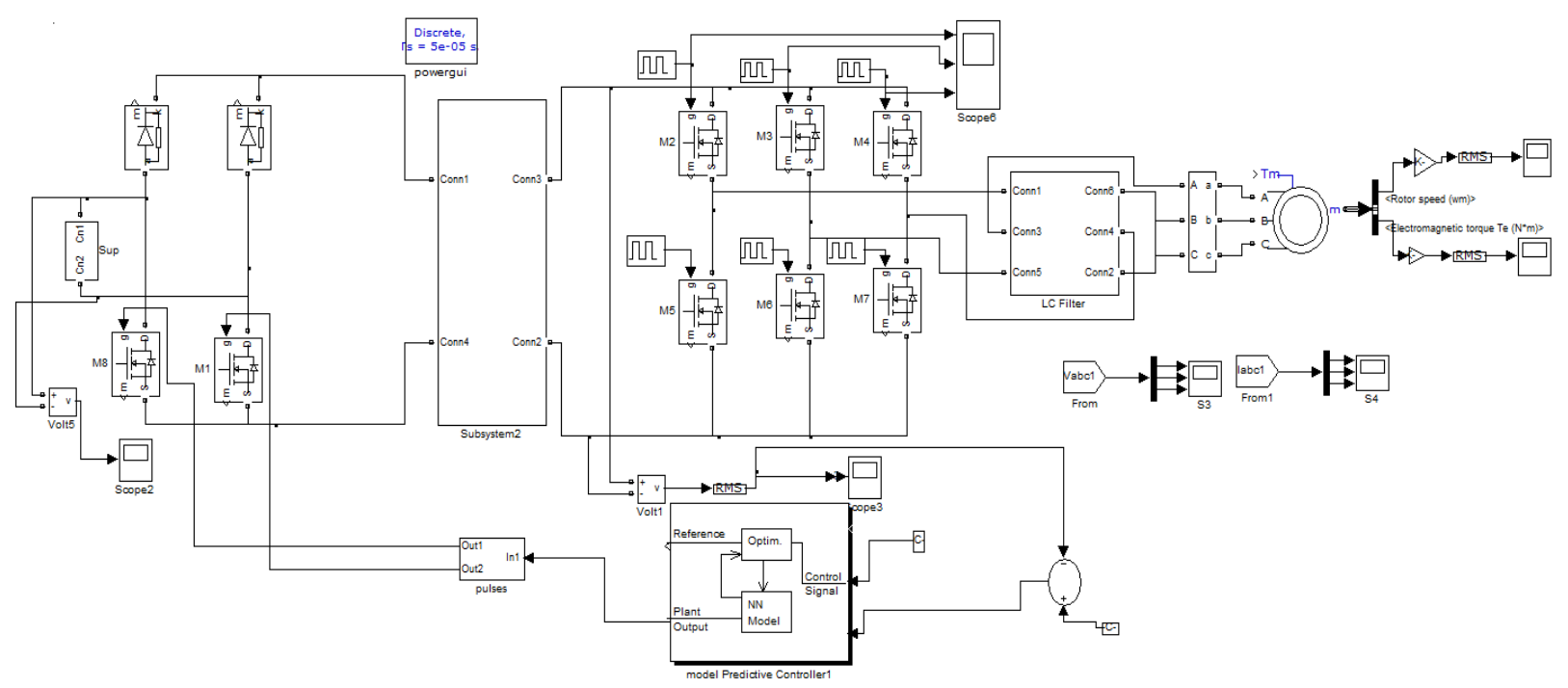

Fig. 16.Simulation diagram of Closed control loop SLQZSI-IM with MP controller

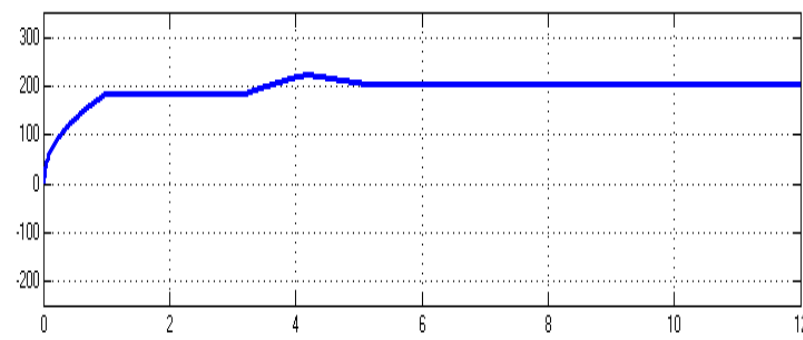

Fig. 17. Output voltage of SLQZSI fed IM with FOPID controller

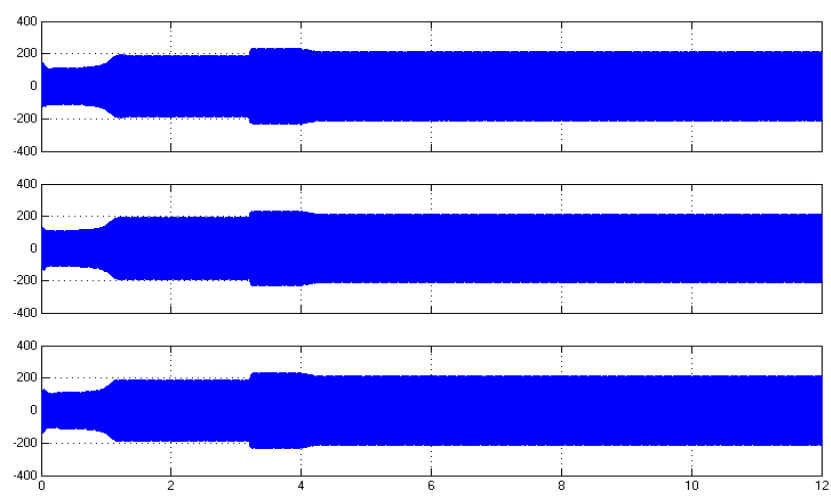

Fig. 18. Voltage across motor load of SLQZSI fed IM with MP controller
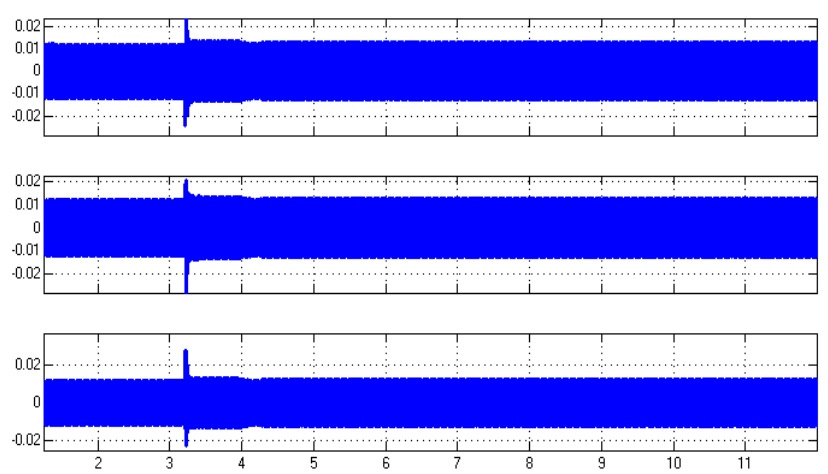

Fig. 19. Motor current of SLQZSI fed IM with MP controller

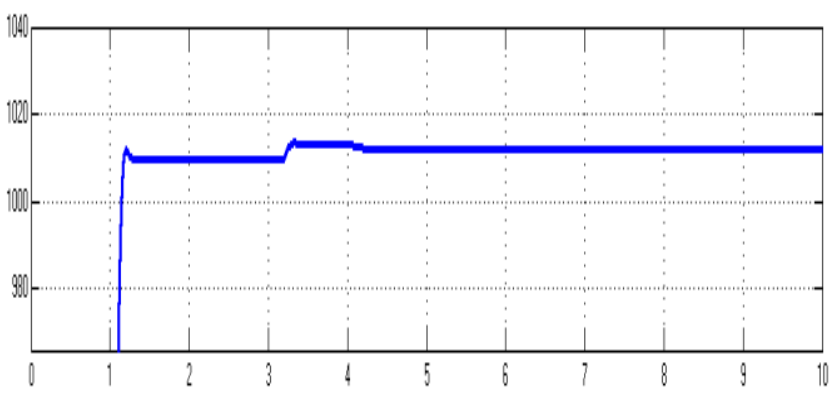

Fig. 20. Motor speed of SLQZSI fed IM with MP controller

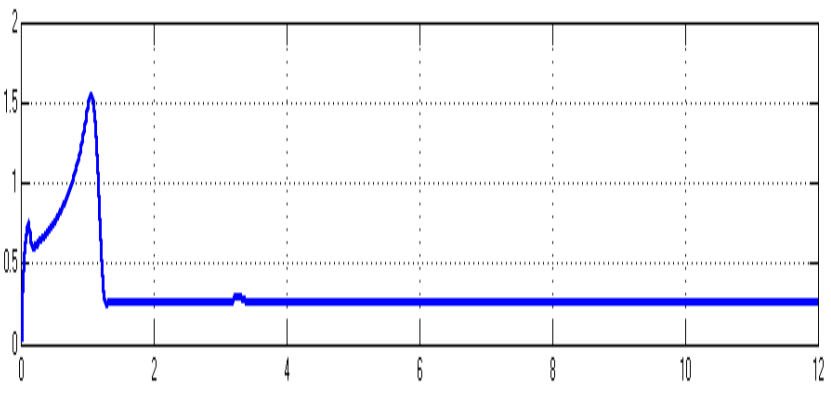

Fig. 21. Motor Torque of SIQZSI fed IM with FOPID controller

Bar chart Comparison of time domain parameters for-current of SLQZSI fed IM using FOPID and MPC is shown in Fig. 22. By using M.P.C, the rise time is decreased from 3.92 Sec to $3.90 \mathrm{Sec}$, the peak time is reduced from 5.33 Sec to $4.14 \mathrm{Sec}$, the settling time is decreased from $6.61 \mathrm{Sec}$ to $5.22 \mathrm{Sec}$ and Steady state-error is decreased from 1.43RPM to 0.8 RPM. 


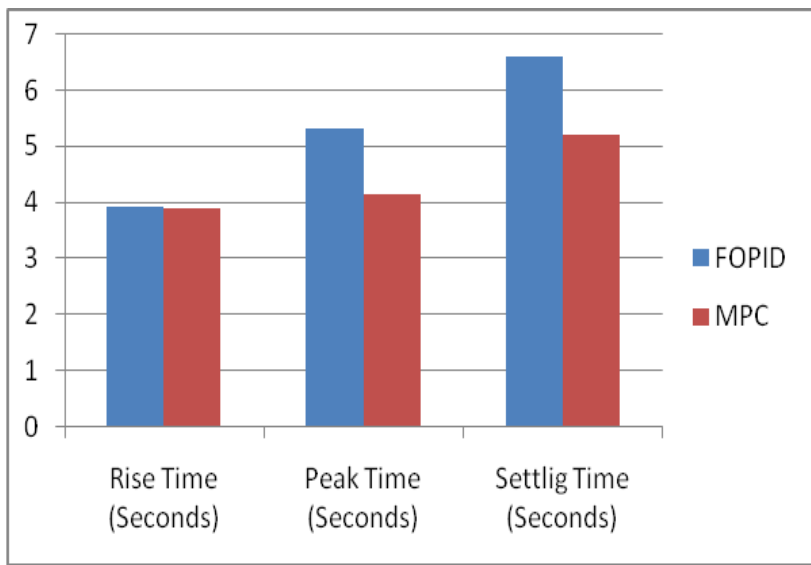

Fig 22. Comparison of SLQZSI fed IM with FOPID controller and MP controller

\section{EXPERIMENTAL RESULTS}

Hardware setup of closed control loop SLQZSI feed IM with MP controller is given in Fig. 23. Table 1 shows hadware parametrs of MP controller fed SLQZSI The hardware omprises of rectifier, SLQZSI, transformer, control circit, inverter and induction motor load. Iput voltage applied to SLQZSI is shown in Fig. 24. Voltage acoss SLQZSI and switching pulses of M1, M3 for SLQSI are given in Fig. 25 and Fig. 26 respectively.. Switching pulses for M2,M4 of SLQZSI and curret throgh induction motor of SLQZSI as show in Fig. 27 and Fig. 28 respectivly.

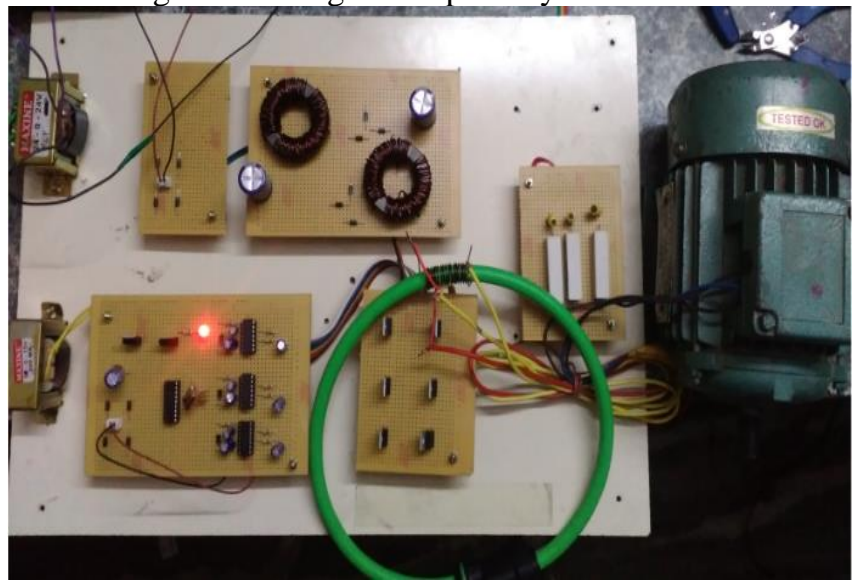

Fig. 23. Hardware setup of closed control loop SLQZSI fed induction motor with MP controller

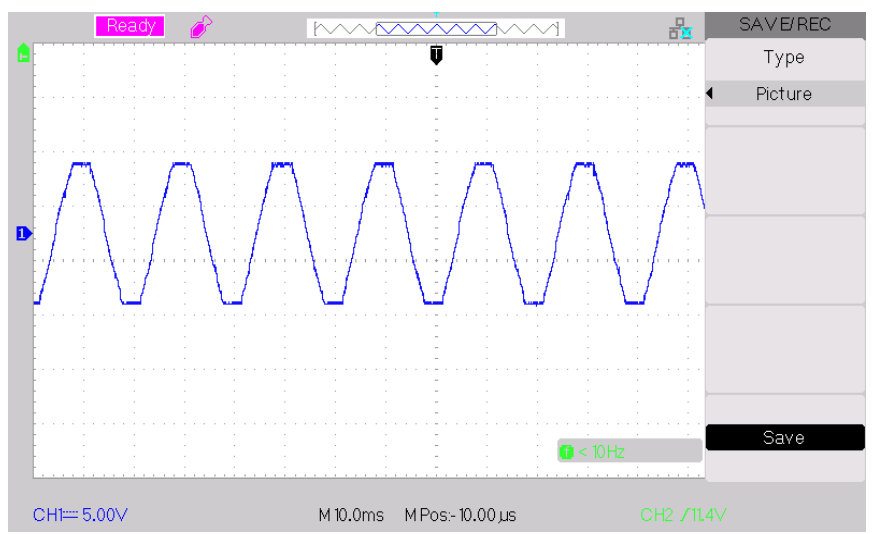

Fig. 24. AC input voltage of SLQSI fed IM with MP controller
Table 1. Hardware parameters of MP controller SLQZSI fed IM

\begin{tabular}{|c|c|}
\hline C1,C2 & $2200 \mu \mathrm{F}$ \\
\hline L1,L2 & $0.5 \mu \mathrm{H}$ \\
\hline L3,L4 & $1.5 \mu \mathrm{F}$ \\
\hline L5,L6,L7 & $50 \mathrm{mH}$ \\
\hline MOSFET(IRF840) & $500 \mathrm{~V} / 8 \mathrm{~A}$ \\
\hline DIODE & $230 \mathrm{~V} / 1 \mathrm{~A}$ \\
\hline PIC & $16 \mathrm{~F} 84 \mathrm{~A}$ \\
\hline DRIVER & IR2110 \\
\hline
\end{tabular}

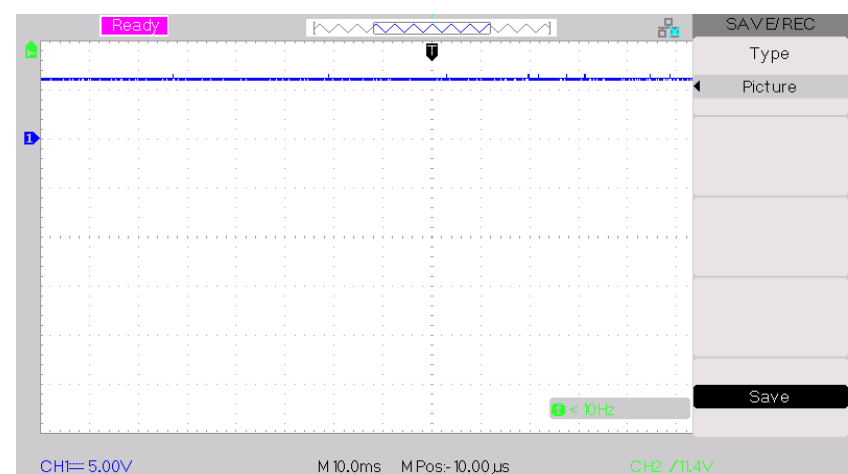

Fig. 25. Output voltage of SLQZSI fed IM with MP controller

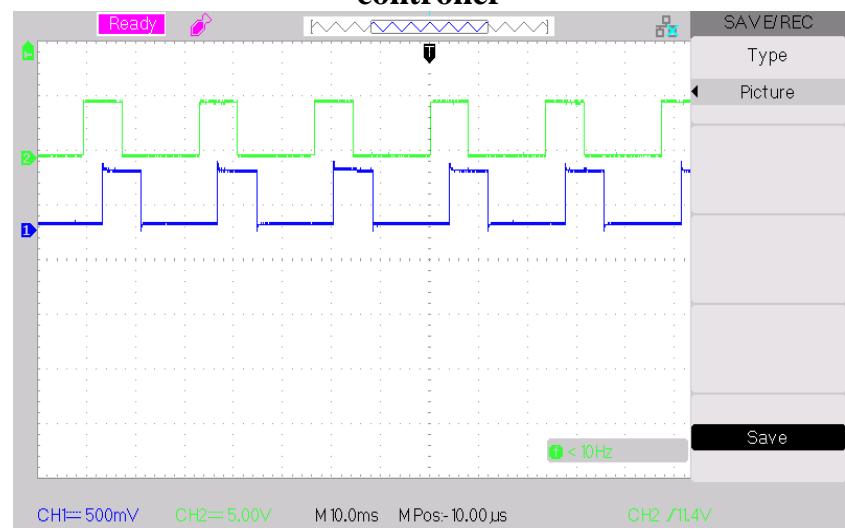

Fig. 26. Switching pulses of M1 and M3 of SLQZSI fed IM with MP controller

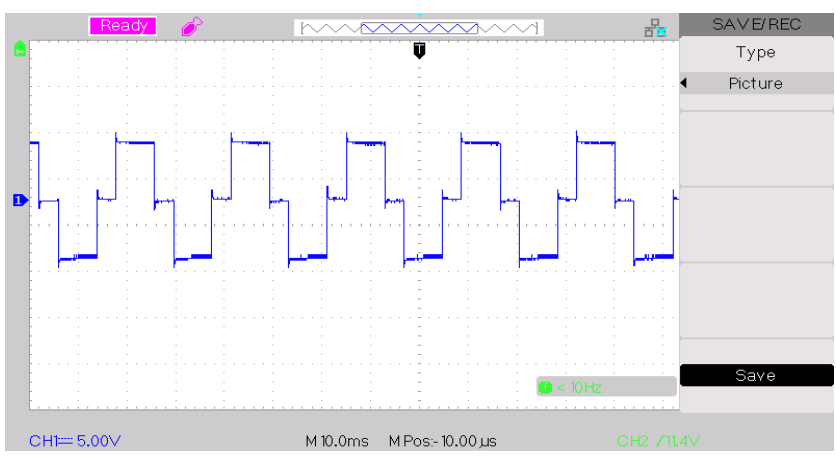

Fig. 27. Switching pulses of M2 and M4 of SLQZSI fed IM with MP controller

Published By:

Retrieval Number: B2981129219/2019@BEIESP 


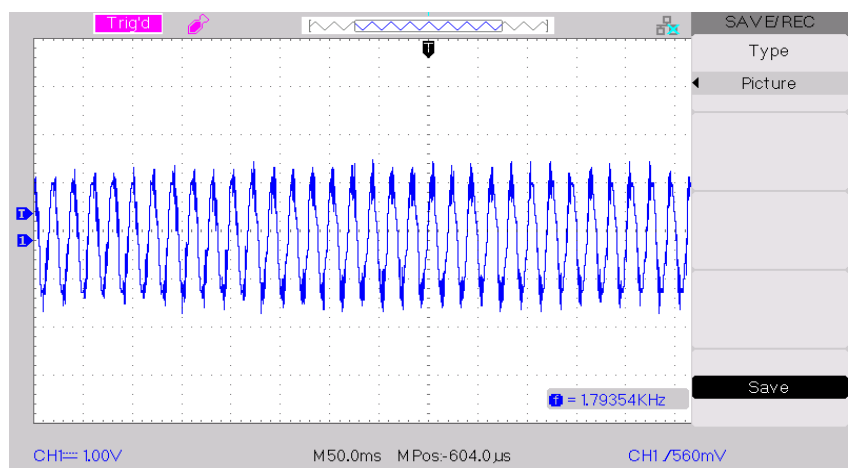

Fig. 28. Current through motor of SLQZSI fed IM with MP controller

\section{CONCLUSION}

"Closed-loop and Open-loop SLQZSI with FOPID and MP controller"are replicated by exercising Matlab simulink. By adopting MPC, the rise time is decreased from 3.92 Sec to $3.90 \mathrm{Sec}$, the peak time is reduced from $5.33 \mathrm{Sec}$ to $4.14 \mathrm{Sec}$, the settling time is reduced from $6.61 \mathrm{Sec}$ to $5.22 \mathrm{Sec}$ and Steady state error is decreased from 1.43 RPM to 0.8 RPM compared with FOPID. Hence, MP controlled SLQZSI is superior to FOPID controller. The benefits of MP controlled SLQZSI fed IM are lessened switch count and improved time response. The drawback of SLQZSI fed IM is increased number of passive components. The Current article pacts with the comparison of MP and FOPID controlled closed loop SLQZSI. Hystersis controlled closed loop SLQZSI can be done in succeeding work.

\section{REFERENCES}

1. V. Jagan, J. Kotturu and S. Das, "Enhanced boost quasi z-source inverters with two switched impedance networks," IEEE transactions on IE, vol. 64, no. 9, pp. 6885-6897, Sept. 2017.

2. D. Sun, B. Ge, W. Liang, H. Abu Rub and F. Z. Peng, "An energy stored quasi z-source cascade multilevel inverter based photovoltaic power generation system," IEEE Transactions on IE, vol. 62, no. 9, pp. 5458-5467, Sept. 2015.

3. W. Liang, Y. Liu, B. Ge and X. Wang, " DC link voltage balance control strategy based on multidimensional modulation technique for quasi z-source cascaded multilevel inverter photovoltaic power system", IEEE Trans., on Industrial Informatics, vol. 14, no. 11, pp. 4905-4915, Nov. 2018.

4. A. Abdelhakim, P. Davari, F. Blaabjerg and P. Mattavelli, "Switching loss reduction in the three phase quasi $\mathrm{z}$-source inverters utilizing modified space vector modulation strategies", IEEE transactions on PE, vol. 33, no. 5, pp. 4045-4060, May. 2018.

5. Y. Gu, Y. Chen and B. Zhang, "Enhanced boost quasi z-source inverter with an active switched z-network", IEEE Transactions on IE, vol. 65, no. 10 , pp. 8372-8381, Oct. 2018.

6. A. Ayad, P. Karamanakos and R. Kennel, "Directmodel predictive current control strategy of quasi $\mathrm{z}$ source inverters", IEEE Transactions on PE, vol. 32, no. 7, pp. 5786-5801, Jul. 2017.

7. Milad Abbasi, Amir Hosein Eslahchi, Mohammad Mardaneh, "Two symmetric extended-boost embedded switched-inductor quasi-z-source inverter with reduced ripple continuous input current”, IEEE Transactions on Industrial Electronics, vol. 65, no. 6, 2018.

8. Vadthya Jagan, Janardhana Kotturu, Sharmili Das, "Enhanced-boost quasi-z-source inverters with two-switched impedance networks, IEEE Transactions on Industrial Electronics" vol. 64, no. 9, 2017.

9. Xiaoquan Zhu, Bo Zhang, Dongyuan Qiu, "A high boost active switched quasi-z-source inverter with low input current ripple”, IEEE Transactions on Industrial Informatics, vol. 15, no. 9, 2019.

10. Mohsen Hasan Babayi Nozadian, Ebrahim Babaei, Seyed Hossein Hosseini, "Steady-state analysis and design considerations of high voltage gain switched z-source inverter with continuous input current", IEEE Transactions on Industrial Electronics, vol. 64, no. 7, 2017.

11. Yuyao He, Yuhao Xu ; Jinping Chen, "New space vector modulation strategies to reduce inductor current ripple of z-source inverter", IEEE Transactions on Power Electronics, vol. 33, no. 3, 2018.
12. Junfeng Liu, Jialei Wu, Jianyong Qiu and Jun Zeng, "Switched z-source/quasi z-source dc-dc converters with reduced passive components for photovoltaic systems", IEEE, vol. 7, no.2, 2019.

13. Petros Karamanakos, Ayman Ayad and Ralph Kennel, "A Variable Switching Point Predictive Current Control Strategy for Quasi-Z-Source Inverters", IEEE Transactions on Industry Applications, vol. 54, no.2, 2018.

14. Haitham Abu-Rub, Omar Ellabban, Mostafa Mosa, "Model Predictive Control of a Grid Connected Quasi-Z-Source Inverter", IEEE International Conference on Industrial Technology (ICIT), 2013.

15. Abualkasim Bakeer, Mohamed A. Ismeil, Mohamed Orabi and Ralph Kennel, "Control of Switched-Inductor Quasi Z-Source Inverter (SL-qZSI) Based on Model Predictive Control Technique (MPC), IEEE International Conference on Industrial Technology (ICIT), 2015.

16. Hyeong-Jun Yoo, Thai Thanh Nguyen and Hak-Man Kim, "MPC with Constant Switching Frequency for Inverter Based Distributed Generations in Microgrid Using Gradient Descent”, Energies 2019.

17. J. Cuenot, "Overall size optimization of a high speed starter using a quasi z-source inverter", IEEE Transactions on transportation electrification, vol. 3, no. 4, pp. 891-900, Dec. 2017.

18. M. Nguyen, T. Tran and Y. Lim, "A family of PWM control strategies for single phase quasi switched boost inverter", IEEE Transactions on PE, vol. 34, no. 2, pp. 1458-1469, Feb. 2019.

\section{AUTHORS PROFILE}

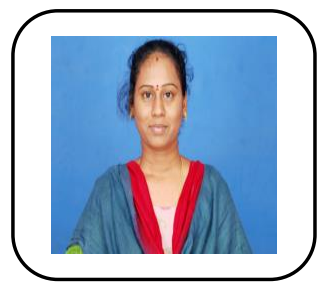

V. Malathi has received her B.E degree in Electrical and Electronics under Madras University, Chennai, India, in 2002 and M.E degree in Applied Electronics under Anna University, Tamil Nadu, in 2005. She is doing job as Assistant Professor with Sri Chandrasekharendra Saraswathi Viswa Mahavidyalaya, Kanchipuram. She has published technical papers in national and international conferences and journals. Her field of interest is Inverters, Electron Devices, Digital Electronics.

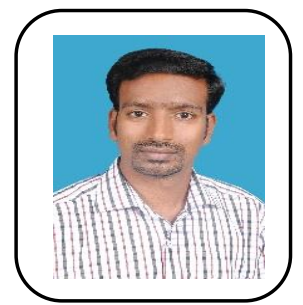

D. Vijayakumar has received the B.E. degree in Electrical and Electronics Engineering under Madras University, India, in 2002, and M.E. degree in Power System under SCSVMV, India, in 2005, and the Ph.D. degree in Electrical Engineering from MANIT, India, in 2010. He was a lecturer from July 2002 to June 2003 in Department of EEE, Pallavan Polytechnic, Kanchipuram. He worked as an Assistant Professor in the Department of EEE, Pallavan College of Engineering, Kanchipuram, from Jan. 2006 to June 2006. While 2009, he has been working as a professor in the School of Electrical Engineering (SELECT), VIT. He has published technical papers in national and international conference and journal. His research field comprises of design of Renewable Energy based inverters for grid, designing and control of dc/dc converters, and power system protection and control. 